\title{
Stage III Adrenal Cortex Carcinoma AJCC v8
}

National Cancer Institute

\section{Source}

National Cancer Institute. Stage III Adrenal Cortex Carcinoma A/CC v8. NCI Thesaurus. Code C141103.

Stage III includes: (T1, N1, M0); (T2, N1, M0); (T3, Any N, M0); (T4, Any N, M0). T1:

Tumor measuring $5 \mathrm{~cm}$ or less in greatest dimension, with no extra-adrenal invasion. T2: Tumor measuring more than $5 \mathrm{~cm}$ in greatest dimension, with no extra-adrenal invasion. T3: Tumor of any size with local invasion but not invading adjacent organs. T4: Tumor of any size that invades adjacent organs (kidney, diaphragm, pancreas, spleen, or liver) or large blood vessels (renal vein or vena cava). N1: Metastasis in regional lymph node(s). M0: No distant metastasis. (from AJCC 8th Ed.) 